Tropical Journal of Pharmaceutical Research March 2020; 19 (3): 565-569

ISSN: $1596-5996$ (print); 1596-9827 (electronic)

(C) Pharmacotherapy Group, Faculty of Pharmacy, University of Benin, Benin City, 300001 Nigeria.

\title{
Protective effect of astragalus injection against myocardial injury in septic young rats via inhibition of JAK/STAT signal pathway and regulation of inflammation
}

\author{
Zhihong Zhao, Xuejing Wang, Xiumin Li, Hongshuang Li, Bin Xu* \\ Department of Pediatric, Liaocheng Second People's Hospital, Linqing, PR China
}

*For correspondence: Email: tky76s@163.com

Sent for review: 7 December 2019

Revised accepted: 28 February 2020

\begin{abstract}
Purpose: To investigate the protective effect of astragalus injection against myocardial injury in septic young rats, and the underlying mechanism of action.

Methods: Seventy-two healthy Sprague Dawley (SD) rats were randomly selected and used to establish a young rat model of sepsis. The young rats were randomly divided into 3 groups: sham, model and astragalus injection groups. Each group had 24 young rats. Serum cardiac troponin I (cTnl), IL-10, IL-6, JAK2 and STAT3 were measured after op.

Results: Compared with sham group, serum cTnl level in the model group was significantly higher, while serum cTnl level of the drug group was significantly lower than that of the model group $(p<0.05)$. Compared with model group, the level of IL-10 in the myocardial tissue of the drug group was significantly elevated, while IL-6 level was lower $(p<0.05)$. Relative to sham rats, myocardial JAK2 and STAT3 protein levels in model rats were high. However, myocardial JAK2 and STAT3 proteins in the drug-treated rats were significantly downregulated, relative to model rats $(p<0.05)$.

Conclusion: Astragalus injection upregulates IL-10 and IL-6 in rats by inhibiting the activation of JAK/STAT signal pathway, and via maintenance of pro-inflammation/anti-inflammation balance. Thus, astragalus exerts protective effect against myocardial injury in sepsis, and can potentially be developed for use as such in clinical practice.
\end{abstract}

Keywords: Astragalus injection, JAK/STAT signal pathway, Pro-inflammatory/anti-inflammatory imbalance, Sepsis, Myocardial injury

\begin{abstract}
This is an Open Access article that uses a fund-ing model which does not charge readers or their institutions for access and distributed under the terms of the Creative Commons Attribution License (http://creativecommons.org/licenses/by/4.0) and the Budapest Open Access Initiative (http://www.budapestopenaccessinitiative.org/read), which permit unrestricted use, distribution, and reproduction in any medium, provided the original work is properly credited.
\end{abstract}

Tropical Journal of Pharmaceutical Research is indexed by Science Citation Index (SciSearch), Scopus, International Pharmaceutical Abstract, Chemical Abstracts, Embase, Index Copernicus, EBSCO, African Index Medicus, JournalSeek, Journal Citation Reports/Science Edition, Directory of Open Access Journals (DOAJ), African Journal Online, Bioline International, Open-J-Gate and Pharmacy Abstracts

\section{INTRODUCTION}

Sepsis is usually a critical and serious complication in clinics. It is also an important cause of multiple organ dysfunction, multiple organ failure and death. Improvements in the understanding of the pathophysiological processes involved in sepsis have revealed that systemic inflammatory response syndrome, compensatory anti-inflammatory response syndrome, and immune paralysis are important characteristics of sepsis [1]. It was recently suggested that in the early stage of sepsis, monocytes/macrophages secrete large amounts of inflammatory factors which directly or indirectly affect myocardial cells, causing myocardial 
injury, myocardial inhibition and even cardiac dysfunction [2].

At present, the key to the treatment of sepsis is to control infection in time and maintain immune homeostasis. According to traditional Chinese medicine, sepsis belongs to the category of exogenous fever which is characterized by empty mark real syndrome [3]. It has been reported that traditional Chinese medicine can achieve good clinical efficacy in the treatment of sepsis [4]. Astragalus is a traditional Chinese medicine. Astragalus injection contains astragaloside $A$, astragalus total saponins and other components, with beneficial effect on qi. Moreover, it contains nourishing elements, strengthens health, eliminates pathogenic factors, nourishes the heart and dredges the pulse. Studies have found that astragalus injection can also regulate the level of inflammatory factors and improve balance between pro-inflammatory and antiinflammatory factors [5]. The protective effect of astragalus Injection on myocardial injury in septic young rats, and its effect on the imbalance between pro-inflammation and anti-inflammation, were determined in the present study.

\section{EXPERIMENTAL}

\section{Animals}

Healthy SD rats $(n=72)$ were purchased from Nanjing Junke Bioengineering Co. Ltd., with production license scxk (ning) 2017-0001). The rats were 5 weeks old, and had a mean weight of $125 \pm 15 \mathrm{~g}$.

This research was approved by the Animal Ethical Committee of Department of Pediatric, Liaocheng Second People's Hospital, Linqing, PR China ((approval no. 201833161)), and was done in line with "Principles of Laboratory Animal Care" [6].

\section{Main equipment and reagents}

The instruments and reagents used, and their manufacturers/suppliers (in brackets) were: paraffin sectioning machine (Shenyang Hengsong Technology Co. Ltd, model: hss7220); low temperature high-speed centrifuge (Shanghai Hetian Scientific Instrument Co. Ltd, model TG18G); biological microscope (Shanghai Precision Instrument Co. Ltd., model: XSP-8C); electronic balance (Beijing Zhongyi HSBC Technology Co. Ltd, model ME204E); immunohistochemical staining kit (Beijing letter) Shengyuan Biomedical Technology Co. Ltd); rabbit anti-human JAK2 polyclonal antibody (Shanghai Xuanling Biotechnology Co. Ltd); rabbit anti-human STAT3 polyclonal antibody (Shanghai Hengfei Biotechnology Co. Ltd.), and astragalus injection (Zhengda Qingqingbao Pharmaceutical Co. Ltd, production batch no. 33020179, specification: 10-ml packs).

\section{Rat grouping and treatments}

To establish the model of sepsis in young rats, the young rats were fed for one week in the laboratory environment at temperature of $23 \pm 3$ ${ }^{\circ} \mathrm{C}$ and humidity of $50 \pm 5 \%$. Three rat groups were used: sham, model, and astragalus injection groups (the drug group). In the shamoperated rats, the animals were anesthetized, opened only, closed immediately, and injected with $5 \mathrm{~mL} / \mathrm{kg}$ saline in tail vein. In the model group, the cecum was ligated and punctured after anesthesia, and the abdomen was closed. After operation, saline was injected into the tail vein at a dose of $5 \mathrm{~mL} / \mathrm{kg}$. In the drug group, the cecum was ligated and punctured after anesthesia, and the abdomen was closed. After operation, the tail vein was injected with $5 \mathrm{ml} / \mathrm{kg}$ astragalus injection. All rats were sacrificed at the end of the experiment.

\section{Therapeutic indicators}

Twelve young rats were selected at 12 and $24 \mathrm{~h}$ after the operation. Abdominal aorta blood (3ml) was centrifuged and the serum samples were kept frozen at $-80{ }^{\circ} \mathrm{C}$ in a refrigerator prior to use.

Serum cardiac troponin I (cTnl) was measured with ELISA. The myocardial tissues of the young rats were isolated, fixed in $4 \%$ formaldehyde solution, and paraffin sections were prepared. The sections were subjected to $H$ \& $E$ staining to observe changes in myocardial morphology.

The myocardial tissue of rats was put into an ice bath of phosphate buffer and centrifuged. The resultant supernatant was subjected to assay of the levels of IL-10 and IL-6 using ELISA.

Immunohistochemistry was applied for the determination of $\mathrm{JAK}_{2}$ and STAT 3 expressions in myocardial tissues of the rats at $24 \mathrm{~h}$.

\section{Statistical analysis}

Quantitative data were compared among multiple groups using single factor and multiple sample mean, while two groups were compared using independent sample $t$-test. All statistical analyses were performed with SPSS version 21.0 software. Differences were considered statistically significant at $p<0.05$. 


\section{RESULTS}

\section{Serum CTN I levels}

As shown in Table 1, serum cTnl level in model rats was markedly elevated, relative to sham rats, and serum cTnl was lower in the drug group than in model group $(p<0.05)$.

Table 1: Serum cTn I levels (mean \pm SD, $n=12$ )

\begin{tabular}{lcc}
\hline \multirow{2}{*}{ Group } & \multicolumn{2}{c}{$\mathbf{c T n ~ I ( p g / L )}$} \\
\cline { 2 - 3 } & \multicolumn{12}{c}{$\boldsymbol{h}$} & $\mathbf{2 4 h}$ \\
\hline Sham & $196.06 \pm 32.34$ & $205.12 \pm 36.92$ \\
Model & $494.44 \pm 67.03^{\mathrm{a}}$ & $821.62 \pm 88.35^{\mathrm{a}}$ \\
Drug & $415.23 \pm 51.29^{\mathrm{ab}}$ & $713.73 \pm 89.63^{\mathrm{ab}}$ \\
$F$ & 105.27 & 226.85 \\
$p$ & $<0.001$ & $<0.001$ \\
\hline${ }^{\mathrm{a} P}<0.05$, vs sham; ${ }^{\mathrm{b}} p<0.05 \mathrm{~B}$, vs model
\end{tabular}

\section{Morphological changes in myocardial tissues of young rats}

Myocardial tissue of sham group was normal in shape, closely arranged and without inflammatory infiltration. In the model group, the myocardial tissue was disordered, abnormal in shape and necrotic, especially after $24 \mathrm{~h}$. However, lesions in the myocardial tissue of the drug group were significantly lower than those in the model group. These results are shown in Figure 1.

\section{Levels of IL-10 and IL-6 in myocardium of young rats}

Table 2 shows marked increases in the levels of IL-10 and IL-6 in model rats, relative to the corresponding levels in sham rats. Myocardial IL10 level in the myocardial tissue of the drugtreated rats was markedly increased, while IL-6 level was markedly decreased, relative to model rats $(p<0.05)$.

Protein expressions of $\mathrm{JAK}_{2}$ and $\mathrm{STAT}_{3}$ in myocardium of young rats $24 \mathrm{~h}$

Compared with the sham-operated rats, myocardial $\mathrm{JAK}_{2}$ and $\mathrm{STAT}_{3}$ proteins were upregulated in model rats. However, drug treatment markedly reduced $\mathrm{JAK}_{2}$ and $\mathrm{STAT}_{3}$ protein levels $(p<0.05)$. These results are depicted in Table 3.

Table 3: Protein expressions of $\mathrm{JAK}_{2}$ and $\mathrm{STAT}_{3}$ in myocardium at $24 \mathrm{~h}(\mathrm{n}=12)$

\begin{tabular}{lcc}
\hline Group & JAK $_{2}$ & STAT $_{3}$ \\
\hline Sham operation & $5.88 \pm 1.38$ & $5.06 \pm 0.98$ \\
Model & $74.88 \pm 7.52^{\mathrm{a}}$ & $46.14 \pm 5.81^{\mathrm{a}}$ \\
Drug & $57.73 \pm 6.55 \mathrm{ab}$ & $36.05 \pm 4.54 \mathrm{ab}$ \\
$F$ & 458.39 & 298.19 \\
$p$ & $<0.001$ & $<0.001$ \\
\hline$P<0.05$, vs sham; ${ }^{\mathrm{b}} p<0.05$, vs model
\end{tabular}

a $P<0.05$, vs sham; ${ }^{b} p<0.05$, vs model
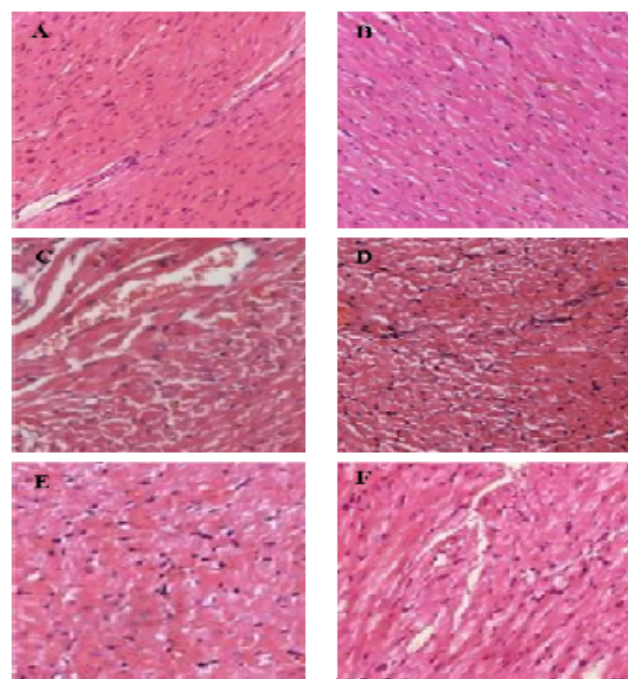

Figure 1: Morphological changes in myocardium. A: $12 \mathrm{~h}$ sham-operated rat; $\mathrm{B}: 24 \mathrm{~h}$ sham-operated rat; C: $12 \mathrm{~h}$ model rat; $\mathrm{D}: 24 \mathrm{~h}$ model rat; $\mathrm{E}: 12 \mathrm{~h}$ drug-treated rat; F: 24 h drug-treated rat.

\section{DISCUSSION}

Sepsis is one of the main causes of death in critically-ill patients, and its treatment has always been a major issue in clinical medicine. Statistics have shown that in the United States, more than 800,000 people suffer from sepsis every year, out of which more than 220000 die. Infection and systemic inflammatory reactions are major manifestations of sepsis. Due to the immature development of physiological functions of various

Table 2: Concentrations of IL-10 and IL-6 in myocardium amongst the groups $(\bar{x} \pm s)$

\begin{tabular}{lcccc}
\hline \multirow{2}{*}{ Group } & \multicolumn{2}{c}{ IL-10 (ng/L) } & \multicolumn{2}{c}{ IL-6 (ng/L) } \\
\cline { 2 - 5 } & $\mathbf{1 2 h}$ & $\mathbf{2 4 h}$ & $\mathbf{1 2 h}$ & $\mathbf{2 4 h}$ \\
\hline Sham & $7.73 \pm 1.15$ & $8.17 \pm 1.59$ & $127.38 \pm 21.54$ & $139.11 \pm 34.66$ \\
Model & $17.48 \pm 2.18^{\mathrm{a}}$ & $27.08 \pm 3.14^{\mathrm{a}}$ & $408.78 \pm 75.01^{\mathrm{a}}$ & $596.96 \pm 79.03^{\mathrm{a}}$ \\
Drug & $22.98 \pm 2.77^{\mathrm{ab}}$ & $34.58 \pm 3.95^{\mathrm{ab}}$ & $325.43 \pm 66.36^{\mathrm{ab}}$ & $447.04 \pm 86.58^{\mathrm{ab}}$ \\
$F$ & 156.19 & 238.22 & 71.67 & 131.27 \\
$P$-value & $<0.001$ & $<0.001$ & $<0.001$ & $<0.001$ \\
\hline
\end{tabular}

${ }^{\mathrm{a}} P<0.05$, compared with sham operation group; ${ }^{\mathrm{b}} p<0.05 \mathrm{~B}$, relative to model rats 

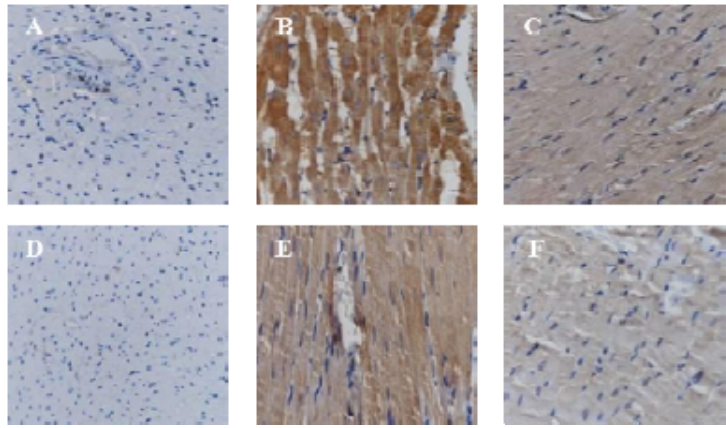

Figure 2: Protein expressions of $\mathrm{JAK}_{2}$ and $\mathrm{STAT}_{3}$ in myocardium at $24 \mathrm{~h}$ in each group. A: Expression of $\mathrm{JAK}_{2}$ in sham operation group; $\mathrm{B}$ : expression of $\mathrm{JAK}_{2}$ in model group; C: expression of $\mathrm{JAK}_{2}$ in drug group; $\mathrm{D}$ : expression of $\mathrm{STAT}_{3}$ in sham operation group; $\mathrm{E}$ : expression of $\mathrm{STAT}_{3}$ in model group; $\mathrm{F}$ : expression of $\mathrm{STAT}_{3}$ in drug group

systems and organs, and low immunity, sepsis in children has become a serious death-related disease in pediatric intensive care units [7].

Sprague-Dawley rats are the first choice for use as animal models of human diseases because of their high degree of similarity with humans with respect to metabolism and diseases, as well as their ease of reproduction. Astragalus injection is a modern Chinese patent medicine which regulates immunity and antioxidant status, and also delays ageing. It has been reported that astragalus injection improves ventricular systolic and diastolic function, and mitigates immune disorders [9]. The present study investigated the influence of astragalus injection on myocardial injury in septic young rats, and the mechanisms involved. One of the cardiac regulatory proteins is CTnl. Under normal conditions, serum cTnl level is low, but when myocardial injury occurs, serum cTnl level is significantly increased. CTnl has a high specificity for myocardial injury, and it is one of the indicators that reflect the degree of myocardial injury with high sensitivity and specificity [9]. The results of this study showed that sepsis caused myocardial damage in young rats, and that astragalus injection exerted protective effect against myocardial damage in the septic young rats.

Some of the core pathological changes in sepsis involve triggering, enhancement and amplification of inflammatory cytokines which are important in the occurrence of sepsis. Under normal conditions, pro-inflammatory and antiinflammatory cytokines are in a dynamic balance at very low levels, thereby ensuring homeostasis. However, when sepsis occurs, a large number of pro-inflammatory and anti-inflammatory factors are released, leading to imbalance between the two factors, organ dysfunction and inflammatory damage to tissue cells $[10,11]$.

It is known that IL-6 is one of the endogenous pyrogen which is vital for the maturation of $B$ cells and the induction of acute phase reactive protein. Studies have found that when sepsis occurs, the level of IL- 6 is significantly increased. Moreover, IL- 6 can be used as a marker of inflammatory response [12]. On the other hand, $\mathrm{IL}-10$ is an endogenous anti-inflammatory factor and an anti-inflammatory cytokine (with important immune regulatory function) which inhibits the expressions of inflammatory cytokines through macrophages [13].

In this study, compared with the model group, IL10 level in the myocardial tissue of the drug group was significantly high, while the concentration of IL- 6 was markedly low, and the levels of IL-10 and IL- 6 in model rats were significantly higher than the corresponding levels in sham rats. These findings suggest that astragalus injection inhibits the expression of IL6 , upregulates the expression of $\mathrm{IL}-10$, and improves imbalance between pro-inflammatory and anti-inflammatory factors. It has been reported that the JAK kinase/signal transducer and activator of transcription (JAK/STAT) signal pathway are involved in the pathophysiology of sepsis, and are also key pathways for a variety of cytokines [14]. The JAK is a non-receptor tyrosine protein which catalyzes tyrosine phosphorylation in cytokine receptor. Moreover, STAT is an activator of transcription. It has been reported that activated STAT enters the nucleus and activates the corresponding target genes, thereby promoting the transcription of mRNA [15]. In this study, compared with the sham operation group, the $\mathrm{JAK}_{2}$ and $\mathrm{STAT}_{3}$ protein expressions in model rats were markedly enhanced, while the protein expressions of $\mathrm{JAK}_{2}$ and $\mathrm{STAT}_{3}$ in drug-treated rats were significantly smaller than the corresponding levels in model rats. These findings suggest that astragalus injection significantly reduces the protein expressions of $\mathrm{JAK}_{2}$ and $\mathrm{STAT}_{3}$ in rat lung tissue, and inhibits the activation of JAK/STAT pathway.

\section{CONCLUSION}

Astragalus injection upregulates the expressions of IL-10 and IL- 6 by inhibiting JAK/STAT signal pathway and the expression of IL-6, and reversal of the imbalance between pro-inflammatory and anti-inflammatory factors. Thus, astragalus exerts protective effect against myocardial injury in sepsis, and may be useful in the therapeutic management of myocardial infarction. 


\section{DECLARATIONS}

\section{Conflict of interest}

No conflict of interest is associated with this work.

\section{Contribution of authors}

We declare that this work was done by the author(s) named in this article and all liabilities pertaining to claims relating to the content of this article will be borne by the authors. All authors read and approved the manuscript for publication. Bin $\mathrm{Xu}$ conceived and designed the study, Zhihong Zhao, Xuejing Wang, Xiumin Li, Hongshuang $\mathrm{Li}$, Bin Xu collected and analysed the data and Zhihong Zhao wrote the manuscript.

\section{Open Access}

This is an Open Access article that uses a funding model which does not charge readers or their institutions for access and distributed under the terms of the Creative Commons Attribution License (http://creativecommons.org/licenses/by/ 4.0) and the Budapest Open Access Initiative (http://www.budapestopenaccessinitiative.org/rea d), which permit unrestricted use, distribution, and reproduction in any medium, provided the original work is properly credited.

\section{REFERENCES}

1. Rhodes A, Evans LE, Alhazzani W, Levy MM, Antonelli $M$, Ferrer R, Kumar A, Sevransky JE, Sprung $C L$, Nunnally $M E$, et al. Surviving Sepsis Campaign: International Guidelines for Management of Sepsis and Septic Shock: 2016. Crit Care Med 2017; 45: 486-552.

2. Waitt PI, Mukaka M, Goodson P, SimuKonda FD, Waitt CJ, Feasey N, Allain TJ, Downie P, Heyderman RS. Sepsis carries a high mortality among hospitalised adults in Malawi in the era of antiretroviral therapy scaleup: A longitudinal cohort study. J Infect 2015; 70: 11-19.

3. Hayakawa M, Yamakawa K, Saito S, Uchino S, Kudo D, lizuka $Y$, Sanui $M$, Takimoto $K$, Mayumi $T$, Ono $K$. Recombinant human soluble thrombomodulin and mortality in sepsis-induced disseminated intravascular coagulation. A multicentre retrospective study. Thromb Haemost 2016; 115: 1157-1166.
4. Liu R, Jiang $H$, Tian $Y$, Zhao $W, W u X$. Astragaloside IV protects against polymicrobial sepsis through inhibiting inflammatory response and apoptosis of lymphocytes. $J$ Surg Res 2016; 200: 315-323.

5. Zhou L, Song Z, Zhou L, Qiu Y, Hu N, Hu Y, Hu X. Protective role of astragalus injection in spinal cord ischemia-reperfusion injury in rats. Neurosciences (Riyadh) 2018; 23: 116-121.

6. World Health Organization. Principles of laboratory animal care. WHO Chron 1985; 39: 51-56.

7. Ustyol L, Peker E, Demir N, Agengin K, Tuncer O. The Use of Acute Peritoneal Dialysis in Critically III Newborns. Med Sci Monit 2016; 22: 1421-1426.

8. Hou YC, Wu JM, Wang MY, Wu MH, Chen KY, Yeh SL, Lin MT. Modulatory Effects oflr, Astragalusir, Polysaccharides on T-Cell Polarization in Mice with Polymicrobial Sepsis. Mediators Inflamm 2015; 2015 : 826319.

9. Tettamanti $C$, Hervet $T$, Grabherr $S$, Palmiere $C$. Elevation of NT-proBNP and cardiac troponins in sepsisrelated deaths: a forensic perspective. Int J Legal Med 2016; 130: 1035-1043.

10. Rice TC, Pugh AM, Caldwell CC, Schneider BSP. Balance Between the Proinflammatory and AntiInflammatory Immune Responses with Blood Transfusion in Sepsis. Crit Care Nurs Clin North Am 2017; 29(3): 331-340.

11. Biro A, Markovich A, Homoki JR, Szöllösi E, Hegedüs C, Tarapcsák S, Lukács J, Stündl L, Remenyik J. Anthocyanin-Rich Sour Cherry Extract Attenuates the Lipopolysaccharide-Induced Endothelial Inflammatory Response. Molecules 2019; 24(19): 3427.

12. de Araujo OR, Salomão $R$, Brunialti $M K C$, da Silva $D C B$, Senerchia AA, de Moraes Costa Carlesse FA, Petrilli AS. Cytokine Kinetics in Febrile Neutropenic Children: Insights on the Usefulness as Sepsis Biomarkers, Influence of Filgrastim, and Behavior of the IL-23/LL-17 Pathway. Mediators Inflamm 2017; 2017: 8291316.

13. Bomans K, Schenz J, Tamulyte S, Schaack D, Weigand MA, Uhle F. Paternal sepsis induces alterations of the sperm methylome and dampens offspring immune responses-an animal study. Clin Epigenetics 2018; 10(1): 89.

14. Ibrahim H, Askar B, Barrow P, Foster N. Dysregulation of JAK/STAT genes by vasoactive intestinal peptide (VIP) in, Salmonella -infected monocytes may inhibit its therapeutic potential in human sepsis. Cytokine 2018; 105(7): 49-56.

15. Yan X, Cheng X, He X, Zheng W, Yuan X, Chen H. HO-1 Overexpressed Mesenchymal Stem Cells Ameliorate Sepsis-Associated Acute Kidney Injury by Activating JAK/stat3 Pathway. Cell Mol Bioeng 2018; 11: 509-518. 